\title{
Anticoagulation Therapy for Atrial Fibrillation
}

\author{
Elaine M. Hylek, MD, MPH ${ }^{1}$ \\ ${ }^{1}$ Department of Medicine, Boston University School of Medicine, \\ Boston, Massachusetts \\ Semin Thromb Hemost 2013;39:147-152.
}

\begin{abstract}
Address for correspondence and reprint requests Elaine M. Hylek, MD, MPH, Department of Medicine, Boston University School of Medicine, 801 Massachusetts Avenue, 2nd Floor Suite, Boston, MA 02118 (e-mail: ehylek@bu.edu).
\end{abstract}

\begin{abstract}
Keywords

- atrial fibrillation

- anticoagulation

- stroke

- hemorrhage

Atrial fibrillation (AF) is the most common significant cardiac rhythm disorder, and its prevalence is increasing worldwide. Atrial fibrillation confers a fivefold increased risk of stroke, and these strokes are associated with significant mortality and disability. The vitamin $\mathrm{K}$ antagonist, warfarin, has been the mainstay of anticoagulant therapy for patients with $A F$, reducing the risk of stroke by $65 \%$. Despite its efficacy, warfarin remains underused in clinical practice because of its variable dose response, diet and medication interactions, and need for frequent monitoring. Stroke prevention in AF has entered an exciting therapeutic era with new classes of targeted anticoagulants that avoid the many pitfalls of the vitamin $\mathrm{K}$ antagonists. Dabigatran, an oral thrombin inhibitor, and the factor Xa inhibitors, rivaroxaban and apixaban, have demonstrated efficacy for stroke prevention and a reduced risk of intracranial hemorrhage relative to warfarin. Translating the efficacy of clinical trials into effective use of these novel agents in clinical practice will require an understanding of their pharmacokinetic profiles, dose selection, and management in select clinical situations.
\end{abstract}

Atrial fibrillation (AF) is the most common cardiac arrhythmia, and its prevalence increases with age. ${ }^{1}$ After the age of 40 years, the lifetime risk of developing AF is approximately 1 in $4 .^{2}$ Among adults aged 55 to 59 years, the prevalence of $\mathrm{AF}$ is $0.7 \%$ and increases to $18 \%$ among individuals older than 85 years. ${ }^{3}$ $\mathrm{AF}$ is a potent risk factor for stroke and systemic embolism conferring, on average, a fivefold increase in risk for these complications. ${ }^{4}$ The attributable risk of stroke for patients with AF increases from $1.5 \%$ at age 50 to 59 years to $23.5 \%$ at age 80 to 89 years. Strokes associated with AF are more severe, reflected by greater mortality and disability, than strokes not associated with $\mathrm{AF}^{5}$ Without prophylaxis, the 30-day mortality of AF-related stroke is approximately $24 \%{ }^{6,7}$

Adjusted-dose warfarin has been shown to reduce the risk of stroke in AF by approximately $60 \%$, in contrast to an estimated $20 \%$ risk reduction with aspirin. ${ }^{8}$ The anticoagulant effect of warfarin is measured by the international normalized ratio (INR) and dosage is titrated to achieve a target level of 2.0 to 3.0. Maintenance of INR values in the therapeutic range is associated with decreased risk of stroke, major hemorrhage, and mortality ${ }^{9-11}$ In addition, ischemic strokes that occur when the INR is in the therapeutic range are less severe compared with those that occur when the INR is less than 2.0. ${ }^{12,13}$ Despite its efficacy, warfarin's narrow therapeutic range, variable dose response, and potential for interaction with numerous medications and diet create barriers to its effectiveness in clinical practice. During the period 2007 to 2009, warfarin was the most frequently implicated drug in emergency hospitalizations for adverse drug events in the United States among adults of age 65 years or older. ${ }^{14}$ The requirement for frequent monitoring coupled with other stated challenges creates a substantial unmet need. Nearly half of eligible individuals with AF are not receiving anticoagulation therapy, and of those who are treated with warfarin, nearly half of the time is spent out of the therapeutic range. $^{15-17}$

\section{Novel Oral Anticoagulants for Stroke Prevention in Atrial Fibrillation}

\section{Summary of the Randomized Trials}

Ximelagatran was the first direct oral thrombin inhibitor approved for stroke prevention in AF, but it was ultimately
Issue Theme Expert Approaches to Common Bleeding and Thrombotic Problems; Guest Editors, Catherine P. M. Hayward, MD, PhD, FRCPC, and Kathryn E. Webert, MD, MSc, FRCPC.
Copyright $\odot 2013$ by Thieme Medical Publishers, Inc., 333 Seventh Avenue, New York, NY 10001, USA. Tel: +1(212) 584-4662.
DOI http://dx.doi.org/ 10.1055/s-0033-1334812. ISSN 0094-6176. 
removed from the market because of liver toxicity. ${ }^{18,19}$ Subsequently dabigatran was proven efficacious, as compared with warfarin, in the Randomized Evaluation of Long-Term Anticoagulation Therapy (RE-LY) trial, which was an open label, noninferiority randomized trial that compared two fixed doses of dabigatran to warfarin. ${ }^{20}$ The $150 \mathrm{mg}$ twice daily dose was found to be superior to warfarin for stroke reduction. This higher dose of dabigatran also reduced ischemic stroke. The $110 \mathrm{mg}$ twice daily dose was shown to be noninferior to warfarin for stroke reduction, with less major hemorrhage. Both doses reduced the risk of intracranial hemorrhage relative to warfarin. Dabigatran was associated with a small risk of myocardial infarction compared with warfarin that did not achieve statistical significance. Despite this risk, dabigatran was associated with reduced cardiovascular mortality. The $150 \mathrm{mg}$ twice daily dose of dabigatran was associated with more gastrointestinal hemorrhage compared with warfarin. Dabigatran received approval in most countries in 2010.

The factor Xa inhibitors, rivaroxaban and apixaban, were being developed and tested in parallel to dabigatran. The Rivaroxaban Once Daily Oral Direct Factor Xa Inhibition Compared with Vitamin K Antagonism for Prevention of Stroke and Embolism Trial in Atrial Fibrillation (ROCKET$\mathrm{AF}$ ) was a double-blind randomized assessment of rivaroxaban, $20 \mathrm{mg} / \mathrm{d}$, versus warfarin. ${ }^{21}$ The study population was at higher risk compared with the other AF trials with $55 \%$ of participants having had an earlier stroke or transient ischemic attack. In ROCKET-AF, rivaroxaban was found to be noninferior to warfarin for stroke prevention in the intention-totreat analysis and superior to warfarin in the on-treatment group. Rivaroxaban was also associated with a reduction in intracranial hemorrhage, but major nonintracranial hemorrhage was increased. Apixaban $5 \mathrm{mg}$ twice daily was compared with warfarin in the Apixaban for Reduction in Stroke and Other Thromboembolic Events in Atrial Fibrillation (ARISTOTLE) double-blind trial. Apixaban was shown to be superior to warfarin for reduction in stroke, and it had less major hemorrhage compared with warfarin and conferred a statistically significant reduction in mortality. ${ }^{22}$ Apixaban was approved by the European Commission in November 2012 for stroke prevention in AF. A summary of the randomized trials that established the efficacy of dabigatran, rivaroxaban, and apixaban compared with warfarin for stroke prevention in AF is shown in - Table 1. Edoxaban is currently being evaluated in a Phase III clinical trial with results expected in 2013. ${ }^{23}$

\section{Current Guideline Recommendations}

Several recently updated guidelines for stroke prevention in AF recommend the novel agents over warfarin and other vitamin K antagonists. ${ }^{24-26}$ The presence of at least one of the major risk factors for stroke, i.e., congestive heart failure, hypertension, age 75 years or older, diabetes mellitus, earlier stroke or transient ischemic attack ( $\mathrm{CHADS}_{2}$ risk factors), would mandate long-term anticoagulation according to all the guidelines in the absence of contraindications. ${ }^{27}$ Other factors to consider in the decision for chronic anticoagulation include age 65 to 74 years, vascular disease, and female sex, which have been formally incorporated into the $\mathrm{CHA}_{2} \mathrm{DS}_{2}$ VAS $_{\mathrm{C}}$ score. ${ }^{28}$ The presence of at least two of these factors weighs in favor of anticoagulation according to most of the guidelines. The focused 2011 update from the American Heart Association/American College of Cardiology Foundation/ Heart Rhythm Society designates the novel anticoagulants as alternatives to warfarin with transition to a novel anticoagulant based on INR control, patient preference, cost, and availability of organized services for warfarin management. ${ }^{29}$

\section{Effective Use in Clinical Practice}

\section{Pharmacokinetic Considerations and Dose Selection}

The factor Xa inhibitors and the direct thrombin inhibitor, dabigatran, lack the dietary interference of warfarin, have significantly fewer drug interactions, do not require routine monitoring, and their shorter half-lives obviate the need for periprocedural bridging in high-risk patients. Compared with warfarin, all these agents substantially reduce the risk of intracerebral hemorrhage, a complication of anticoagulation that is associated with a $46 \%$ mortality. ${ }^{30} \mathrm{~A}$ significant distinction of the novel oral anticoagulants from warfarin is their reliance on renal mechanisms for drug clearance, which is $80 \%$ for dabigatran, $33 \%$ for rivaroxaban, and $25 \%$ for apixaban. Renal function must therefore be assessed before initiation of these agents and the dose selected according to the estimated glomerular filtration rate (GFR) using the Cockcroft - Gault equation ([140-age] $\times$ [weight in kilogram $] \times[0.85$ if female]/[72 $\times$ creatinine $])^{31}$ For individuals with $\mathrm{AF}$ and a GFR greater than $30 \mathrm{~mL} / \mathrm{min}$, the recommended dose of dabigatran is $150 \mathrm{mg}$ twice daily. In many countries, a $110 \mathrm{mg}$ twice daily dose is available for individuals deemed to be at the highest risk for bleeding, e.g., age 80 years and older. In the United States, a $75 \mathrm{mg}$ twice daily dose of dabigatran is approved for individuals with a GFR of 15 to $30 \mathrm{~mL} / \mathrm{min}$. The approved dose of rivaroxaban for stroke prevention in AF is $20 \mathrm{mg} / \mathrm{d}$ with GFR greater than $50 \mathrm{~mL} /$ min and $15 \mathrm{mg} / \mathrm{d}$ if the GFR is 15 to $50 \mathrm{~mL} / \mathrm{min}$. In the ARISTOTLE trial, a reduced apixaban dose of $2.5 \mathrm{mg}$ twice daily was indicated for participants with two of the following: age 80 years and greater, weight $60 \mathrm{~kg}$ or less, or creatinine $1.5 \mathrm{mg} / \mathrm{dL}(133 \mu \mathrm{mol} / \mathrm{L})$ or greater.

\section{Drug Interactions and Transitions}

Dabigatran, rivaroxaban, apixaban, and edoxaban are permeability-glycoprotein (P-gp) substrates. ${ }^{32} \mathrm{P}$-gp is an intracellular drug transport system that plays an important role in drug absorption and distribution. ${ }^{33}$ There are P-gp receptors on the surfaces of the gastrointestinal tract, brain, liver, and kidney. Medications that inhibit P-gp increase the absorption and serum concentrations of drugs dependent on P-gp transport, and medications that induce P-gp, e.g., rifampin, decrease the absorption and serum concentrations of drugs dependent on P-gp transport. Consequently, concomitant use of potent P-gp inhibitors/inducers with dabigatran, rivaroxaban, and apixaban should be avoided. Among individuals with moderate renal impairment, i.e., GFR 30 to $50 \mathrm{~mL} / \mathrm{min}$, 
Table 1 Summary of randomized trials evaluating new anticoagulants for treatment of atrial fibrillation

\begin{tabular}{|c|c|c|c|c|}
\hline Trial & Characteristics & Study drug & $\begin{array}{l}\text { Stroke or systemic } \\
\text { embolism event rate, } \\
\% / y \text { study drug vs warfarin }\end{array}$ & $\begin{array}{l}\text { Major hemorrhage } \\
\text { event rate, \%/y } \\
\text { study drug vs } \\
\text { warfarin }\end{array}$ \\
\hline $\begin{array}{l}\text { RE-LY20 } \\
\text { open-label }\end{array}$ & $\begin{array}{l}\text { Age, mean } 71 \\
\text { CHADS }_{2} \text {, mean } 2.1 \\
\text { TTR } \% \text {, mean } 64 \\
\mathrm{CrCl}<50 \mathrm{~mL} / \min 19 \%\end{array}$ & $\begin{array}{l}\text { Dabigatran } 150 \mathrm{mg}^{\mathrm{a}} \\
\text { Dabigatran } 110 \mathrm{mg}^{\mathrm{a}}\end{array}$ & $\begin{array}{l}1.1 \text { vs } 1.7, \text { RR } 0.66 \\
(0.53-0.82) \\
1.5 \text { vs } 1.7, \text { RR } 0.91 \\
(0.74-1.11)\end{array}$ & $\begin{array}{l}3.1 \text { vs } 3.4, \text { RR } 0.93 \\
(0.81-1.07) \\
2.7 \text { vs } 3.4, \text { RR } 0.80 \\
(0.69-0.93)\end{array}$ \\
\hline $\begin{array}{l}\text { ROCKET-AF } \\
\text { double-blind }\end{array}$ & $\begin{array}{l}\text { Age, median } 73 \\
\text { CHADS } 2 \text {, mean } 3.5 \\
\text { TTR \%, mean } 55 \\
\mathrm{CrCl}>30-50 \mathrm{~mL} / \min 21 \%\end{array}$ & Rivaroxaban 20 mg & $\begin{array}{l}2.1 \text { vs } 2.4, \text { HR } 0.88 \\
(0.75-1.03)\end{array}$ & $\begin{array}{l}3.6 \text { vs } 3.4, \text { HR } 1.04 \\
(0.90-1.20)\end{array}$ \\
\hline $\begin{array}{l}\text { ARISTOTLE } 22 \\
\text { double-blind }\end{array}$ & $\begin{array}{l}\text { Age, median } 70 \\
\text { CHADS }_{2} \text {, mean } 2.1 \\
\text { TTR \%, mean } 62 \\
\mathrm{CrCl}>30-50 \mathrm{~mL} / \min 15 \%\end{array}$ & Apixaban 5 mg & $\begin{array}{l}1.3 \text { vs } 1.6, \text { HR } 0.79 \\
(0.66-0.95)\end{array}$ & $\begin{array}{l}2.1 \text { vs } 3.1, \text { HR } 0.69 \\
(0.60-0.80)\end{array}$ \\
\hline
\end{tabular}

Abbreviations: ARISTOTLE, Apixaban for Reduction in Stroke and Other Thromboembolic Events in Atrial Fibrillation; $\mathrm{CrCl}$, creatinine clearance; $\mathrm{HR}$, hazard ratio; mg, milligram; RE-LY, Randomized Evaluation of Long-Term Anticoagulation Therapy; ROCKET-AF, The Rivaroxaban Once Daily Oral Direct Factor Xa Inhibition Compared with Vitamin K Antagonism for Prevention of Stroke and Embolism Trial in Atrial Fibrillation; RR, relative risk; TTR, time in therapeutic range; vs, versus; $y$, year.

${ }^{a}$ Twice daily.

treatment with the combination of ketoconazole and dronedarone (two P-gp inhibitors) with dabigatran resulted in high drug levels, similar to those observed in severe renal impairment. A dose reduction should be strongly considered in these patients. In addition to their renal elimination, rivaroxaban and apixaban are metabolized via CYP3A4. Rivaroxaban should not be used with drugs that are combined potent P-gp and strong CYP3A4 inhibitors (e.g., ketoconazole, itraconazole, lopinavir/ritonavir, ritonavir, indinavir/ritonavir, and conivaptan) or with drugs that are combined P-gp and strong CYP3A4 inducers (e.g., carbamazepine, phenytoin, and rifampin). Similar recommendations are anticipated for apixaban. Health care providers are encouraged to consult package inserts for specific dosing recommendations.

Guidance regarding transitions from one anticoagulant to another is driven by the expected time of onset ( 2 to 3 hours) of the novel drugs and time of offset (half-life approximately 10 hours). The rapid onset and shorter half-lives of the novel anticoagulants are in stark contrast to the delayed antithrombotic effect of warfarin and its average half-life of 36 to 42 hours. ${ }^{34}$ When transitioning a patient from warfarin, dabigatran can be safely started when the INR is less than 2.0. For rivaroxaban, initiation is recommended when the INR is less than 3.0. Conversely, if switching from a novel anticoagulant to warfarin, some overlap of treatment may be necessary given the delay in warfarin's antithrombotic effect. The increase in events that occurred at the end of both the ROCKET-AF and ARISTOTLE trials underscores the importance of timely attainment of the therapeutic range if transitioning to warfarin.

\section{Potential Challenges with Clinical Use and Unanswered Questions}

Translating the efficacy demonstrated in randomized trials into effective use in clinical practice depends on the similari- ties between the population studied and the intended target population. Participants in clinical trials are often younger, more ambulatory, and less acutely ill. The structure imposed by the trial design and trial personnel serves to reinforce drug adherence. Anticipating potential challenges with use of these agents will enhance their effectiveness in clinical practice as trial experience does not inform optimal management for all patient subgroups and clinical situations (-Table 2).

\section{Adherence}

Nonadherence (or "noncompliance") threatens the effectiveness of any drug. Studies have shown that 25 to $50 \%$ of individuals do not take their medications as prescribed. ${ }^{35,36}$ Given the shorter half-lives of the novel anticoagulants, missed doses, whether intentional or unintentional, may increase susceptibility to adverse events. Warfarin's half-life of 40 hours provides a "buffer" to sporadic nonadherence. Patient education with subsequent reinforcement will be integral to achieving trial-level endpoints.

\section{Renal Dysfunction}

Another area of uncertainty in real-world practice is the safety and practical management of the novel anticoagulants in the setting of acute kidney injury, wide fluctuations in renal function, and advanced renal disease. Warfarin therapy in this group of AF patients is problematic, associated with increased hemorrhage and INR variability. ${ }^{37}$ It is important to note that individuals with a GFR less than $30 \mathrm{~mL} / \mathrm{min}$ were excluded from the trials of new oral anticoagulants (less than $25 \mathrm{~mL}$ / min for apixaban) and that approximately one in five participants had moderate renal impairment. ${ }^{38-40}$ Baseline determination of GFR does not necessarily inform on longitudinal changes to renal function, particularly for older patients and patients with heart failure, polypharmacy, or frequent 
Table 2 Potential challenges with novel agents as anticoagulant therapy for AF and current knowledge gaps for these agents

\begin{tabular}{|l|l|}
\hline Adherence & Shorter half-lives may render novel agents more vulnerable to nonadherence \\
\hline Fluctuations in renal function & $\begin{array}{l}\text { Practical implications of dose reductions based on transient decrements in GFR and dose } \\
\text { escalations based on recovery of renal function }\end{array}$ \\
\hline Moderate renal impairment & $\begin{array}{l}\text { Uncertain effectiveness of periodic monitoring of renal function given vagaries of } \\
\text { acute kidney injury }\end{array}$ \\
\hline Intracranial hemorrhage & Blood pressure control, age of trial participants \\
\hline Gastrointestinal hemorrhage & $\begin{array}{l}\text { Timing of resumption of anticoagulation; uncertain differential effects across anticoagulants } \\
\text { based on anatomic location }\end{array}$ \\
\hline Translation across indications & $\begin{array}{l}\text { Different dose, different dosing frequency, untested or unapproved indications, e.g., } \\
\text { prosthetic heart valve }\end{array}$ \\
\hline Meversal & $\begin{array}{l}\text { Life-threatening hemorrhage, major trauma, urgent procedure; limited data for novel } \\
\text { agents; limited data for warfarin that reversal affects bleeding outcomes }\end{array}$ \\
\hline Postprocedure & $\begin{array}{l}\text { Safety of thrombolytic therapy in setting of acute stroke; clinical management in setting } \\
\text { of major hemorrhage, urgent procedure, elevated drug levels; measure of adherence }\end{array}$ \\
\hline Acute coronary syndrome & Rapid onset, need for assured hemostasis before resumption \\
\hline Well-controlled INR & $\begin{array}{l}\text { Triple therapy too high risk for most patients, i.e., dual antiplatelet therapy combined } \\
\text { with anticoagulant dose for AF }\end{array}$ \\
\hline
\end{tabular}

Abbreviations: AF, atrial fibrillation; GFR, glomerular filtration rate; INR, international normalized ratio.

hospitalizations. Current recommendations for both dabigatran and rivaroxaban are to monitor renal function on a yearly basis and in clinical situations that may be associated with a decline in renal function. Because fluctuations in renal function are often acute and not predictable, preemptive dosereduction strategies to minimize bleeding risk may not be effectual. Temporarily withholding the drug should suffice in most instances of acute kidney injury, similar to the strategies used when patients taking warfarin have an elevated INR. Based on pharmacokinetic data, the estimated elimination half-life for dabigatran with GFR less than $30 \mathrm{~mL} / \mathrm{min}$ is 27.5 hours compared with 13.8 hours with normal renal function. For rivaroxaban and apixaban, which are both less dependent on renal clearance than dabigatran, the magnitude of the impact is less: 9.5 hours versus 8.3 for rivaroxaban and 17.3 hours versus 15.1 for apixaban. ${ }^{41}$ Management and outcomes of patients who require urgent procedures and of patients with serious bleeding in the setting of elevated drug levels are uncertain and warrant further study. ${ }^{42}$

\section{Major Hemorrhage, Gastrointestinal Hemorrhage, and Recurrent Hemorrhage}

Compared with warfarin, all the novel anticoagulants reduce the risk of intracranial hemorrhage associated with anticoagulation for stroke. Attainment of the magnitude of the treatment benefits seen in clinical trials will require attention to other known risk factors for intracranial hemorrhage, e.g., blood pressure, concomitant antiplatelet therapy, neurovasculopathies (amyloid angiopathy and leukoaraiosis), binge alcohol drinking, and trauma. Although the most lethal complication of anticoagulant therapy is reduced, the more frequent complication of anticoagulation, gastrointestinal hemorrhage, was increased with rivaroxaban and the higher dose of dabigatran compared with warfarin. ${ }^{20,21}$ Gastrointes- tinal hemorrhage is not associated with the same level of morbidity and mortality as intracranial hemorrhage, but it frequently leads to hospitalization and cessation of therapy. ${ }^{14}$ Deciphering the location and mechanism of gastrointestinal hemorrhage among older adults will facilitate targeted prevention strategies (e.g., treatment with proton pump inhibitors) and help to mitigate bleeding complications. As individuals with a propensity for bleeding were not eligible for the AF trials, evidence to guide optimal management for these patients is lacking, particularly related to the timing of drug resumption and the benefit, if any, of switching to another agent.

\section{Translation Across Indication}

Despite the challenges of warfarin, the therapeutic range is uniform across most indications. Use of the novel anticoagulants for prosthetic heart valves is contraindicated. In addition, the dose and dosing frequency of the novel agents may differ for different indications; for example, distinct from AF, twice daily doses of rivaroxaban $(2.5 \mathrm{mg}$ and $5 \mathrm{mg}$ ) were tested in acute coronary syndromes and for the first 3 weeks of treatment for acute venous thromboembolism $(15 \mathrm{mg})$. Health care providers will need to remain abreast of approved indications and indication-specific dosing recommendations.

\section{Warfarin Anticoagulation for Atrial Fibrillation}

For individuals without access to the novel drugs, who are intolerant to the novel drugs, or who are unwilling or unable (prosthetic heart valve) to switch to a novel drug, warfarin remains a viable treatment option, particularly if well controlled. Although earlier trial reports seemed to negate the influence of time in the therapeutic range (TTR) (center-based 
analysis), a recent report demonstrates that improved warfarin dosing, via wider use of a dosing algorithm, improved center TTR in the RE-LY trial with a resultant reduction in adverse events. ${ }^{43,44}$ For individuals taking warfarin with excellent INR control, the overall net clinical benefit of switching to a novel anticoagulant is not as clear. ${ }^{29}$

\section{Conclusion}

The prevalence of AF is increasing worldwide, reflecting an aging population, aging vasculature, and rising rates of obesity. On average, AF increases the risk of stroke fivefold. Strokes related to AF confer a 30-day mortality of $24 \%$. The frequency and severity of these strokes are reduced with anticoagulation. The advent of the direct thrombin inhibitor, dabigatran, and factor Xa inhibitors, rivaroxaban and apixaban, heralds a new era for stroke prevention in AF. Anticipating potential challenges with use of these agents will enhance their effectiveness in clinical practice.

\section{Acknowledgment}

Dr. Hylek is supported by National Institutes of Health grant R01NS070307. She has served on the advisory boards of the following pharmaceutical companies: Bayer, Boehringer-Ingleheim, Bristol-Myers Squibb, Daiichi Sankyo, Johnson and Johnson, and Pfizer.

\section{References}

1 Miyasaka Y, Barnes ME, Gersh BJ, et al. Secular trends in incidence of atrial fibrillation in Olmsted County, Minnesota, 1980 to 2000, and implications on the projections for future prevalence. Circulation 2006;114(2):119-125

2 Lloyd-Jones DM, Wang TJ, Leip EP, et al. Lifetime risk for development of atrial fibrillation: the Framingham Heart Study. Circulation 2004;110(9):1042-1046

3 Heeringa J, van der Kuip DA, Hofman A, et al. Prevalence, incidence and lifetime risk of atrial fibrillation: the Rotterdam study. Eur Heart J 2006;27(8):949-953

4 Wolf PA, Abbott RD, Kannel WB. Atrial fibrillation as an independent risk factor for stroke: the Framingham Study. Stroke 1991;22 (8):983-988

5 Jørgensen HS, Nakayama H, Reith J, Raaschou HO, Olsen TS. Acute stroke with atrial fibrillation. The Copenhagen Stroke Study. Stroke 1996;27(10):1765-1769

6 Sandercock P, Bamford J, Dennis M, et al. Atrial fibrillation and stroke: prevalence in different types of stroke and influence on early and long term prognosis (Oxfordshire community stroke project). BMJ 1992;305(6867):1460-1465

7 Lin HJ, Wolf PA, Kelly-Hayes M, et al. Stroke severity in atrial fibrillation. The Framingham Study. Stroke 1996;27(10): 1760-1764

8 Hart RG, Pearce LA, Aguilar MI. Meta-analysis: antithrombotic therapy to prevent stroke in patients who have nonvalvular atrial fibrillation. Ann Intern Med 2007;146(12):857-867

9 White HD, Gruber M, Feyzi J, et al. Comparison of outcomes among patients randomized to warfarin therapy according to anticoagulant control: results from SPORTIF III and V. Arch Intern Med 2007;167(3):239-245

10 Gallagher AM, Setakis E, Plumb JM, Clemens A, van Staa TP. Risks of stroke and mortality associated with suboptimal anticoagulation in atrial fibrillation patients. Thromb Haemost 2011;106(5): 968-977

11 Wan Y, Heneghan C, Perera R, et al. Anticoagulation control and prediction of adverse events in patients with atrial fibrillation: a systematic review. Circ Cardiovasc Qual Outcomes 2008;1(2): 84-91

12 Hylek EM, Go AS, Chang Y, et al. Effect of intensity of oral anticoagulation on stroke severity and mortality in atrial fibrillation. N Engl J Med 2003;349(11):1019-1026

13 O'Donnell M, Oczkowski W, Fang J, et al; Investigators of the Registry of the Canadian Stroke Network. Preadmission antithrombotic treatment and stroke severity in patients with atrial fibrillation and acute ischaemic stroke: an observational study. Lancet Neurol 2006;5(9):749-754

14 Budnitz DS, Lovegrove MC, Shehab N, Richards CL. Emergency hospitalizations for adverse drug events in older Americans. N Engl J Med 2011;365(21):2002-2012

15 Waldo AL, Becker RC, Tapson VF, Colgan KJ; NABOR Steering Committee. Hospitalized patients with atrial fibrillation and a high risk of stroke are not being provided with adequate anticoagulation. J Am Coll Cardiol 2005;46(9):1729-1736

16 Friberg L, Hammar N, Ringh M, Pettersson H, Rosenqvist M. Stroke prophylaxis in atrial fibrillation: who gets it and who does not? Report from the Stockholm Cohort-study on Atrial Fibrillation (SCAF-study). Eur Heart J 2006;27(16):1954-1964

17 Ogilvie IM, Newton N, Welner SA, Cowell W, Lip GY. Underuse of oral anticoagulants in atrial fibrillation: a systematic review. Am J Med 2010;123(7):638-645, e4

18 Olsson SB; Executive Steering Committee of the SPORTIF III Investigators. Stroke prevention with the oral direct thrombin inhibitor ximelagatran compared with warfarin in patients with non-valvular atrial fibrillation (SPORTIF III): randomised controlled trial. Lancet 2003;362(9397):1691-1698

19 Albers GW, Diener HC, Frison L, et al; SPORTIF Executive Steering Committee for the SPORTIF V Investigators. Ximelagatran vs warfarin for stroke prevention in patients with nonvalvular atrial fibrillation: a randomized trial. JAMA 2005;293(6): 690-698

20 Connolly SJ, Ezekowitz MD, Yusuf S, et al; RE-LY Steering Committee and Investigators. Dabigatran versus warfarin in patients with atrial fibrillation. N Engl J Med 2009;361(12):1139-1151

21 Patel MR, Mahaffey KW, Garg J, et al; ROCKET AF Investigators. Rivaroxaban versus warfarin in nonvalvular atrial fibrillation. $\mathrm{N}$ Engl J Med 2011;365(10):883-891

22 Granger CB, Alexander JH, McMurray JJV, et al; ARISTOTLE Committees and Investigators. Apixaban versus warfarin in patients with atrial fibrillation. N Engl J Med 2011;365(11):981-992

23 Ruff CT, Giugliano RP, Antman EM, et al. Evaluation of the novel factor Xa inhibitor edoxaban compared with warfarin in patients with atrial fibrillation: design and rationale for the Effective aNticoaGulation with factor xA next GEneration in Atrial Fibrillation-Thrombolysis In Myocardial Infarction study 48 (ENGAGE AFTIMI 48). Am Heart J 2010;160(4):635-641

24 Skanes AC, Healey JS, Cairns JA, et al; Canadian Cardiovascular Society Atrial Fibrillation Guidelines Committee. Focused 2012 update of the Canadian Cardiovascular Society atrial fibrillation guidelines: recommendations for stroke prevention and rate/ rhythm control. Can J Cardiol 2012;28(2):125-136

25 Camm AJ, Lip GY, De Caterina R, et al; ESC Committee for Practice Guidelines (CPG); Document Reviewers. 2012 focused update of the ESC Guidelines for the management of atrial fibrillation: an update of the 2010 ESC Guidelines for the management of atrial fibrillation. Developed with the special contribution of the European Heart Rhythm Association. Eur Heart J 2012;33(21): 2719-2747

26 You JJ, Singer DE, Howard PA, et al. Antithrombotic therapy for atrial fibrillation: antithrombotic therapy and prevention of thrombosis, 9th ed: American College of Chest Physicians 
Evidence-Based Clinical Practice Guidelines. Chest 2012;141(2 Suppl):e531S-e575S

27 Gage BF, Waterman AD, Shannon W, Boechler M, Rich MW, Radford MJ. Validation of clinical classification schemes for predicting stroke: results from the National Registry of Atrial Fibrillation. JAMA 2001;285(22):2864-2870

28 Lip GY, Nieuwlaat R, Pisters R, Lane DA, Crijns HJ. Refining clinical risk stratification for predicting stroke and thromboembolism in atrial fibrillation using a novel risk factor-based approach: the euro heart survey on atrial fibrillation. Chest 2010;137(2): 263-272

29 Fuster V, Rydén LE, Cannom DS, et al; American College of Cardiology Foundation/American Heart Association Task Force. 2011 ACCF/AHA/HRS focused updates incorporated into the ACC/ AHA/ESC 2006 guidelines for the management of patients with atrial fibrillation: a report of the American College of Cardiology Foundation/American Heart Association Task Force on practice guidelines. Circulation 2011;123(10):e269-e367

30 Hylek EM, Singer DE. Risk factors for intracranial hemorrhage in outpatients taking warfarin. Ann Intern Med 1994;120(11): 897-902

31 Cockcroft DW, Gault MH. Prediction of creatinine clearance from serum creatinine. Nephron 1976;16(1):31-41

32 Walenga JM, Adiguzel C. Drug and dietary interactions of the new and emerging oral anticoagulants. Int J Clin Pract 2010;64(7): 956-967

33 Lin JH, Yamazaki M. Role of P-glycoprotein in pharmacokinetics: clinical implications. Clin Pharmacokinet 2003;42(1):59-98

34 Ageno W, Gallus A, Wittkowsky A, et al. Oral anticoagulant therapy: antithrombotic therapy and prevention of thrombosis. ACCP evidence-based guidelines (Ninth Edition). Chest 2012;141 (2 Suppl):e44S-e88S

35 Avorn J. The relative cost-effectiveness of anticoagulants: obvious, except for the cost and the effectiveness. Circulation 2011;123 (22):2519-2521
36 Cutler DM, Everett W. Thinking outside the pillbox-medication adherence as a priority for health care reform. N Engl J Med 2010;362(17):1553-1555

37 Reinecke H, Brand E, Mesters R, et al. Dilemmas in the management of atrial fibrillation in chronic kidney disease. J Am Soc Nephrol 2009;20(4):705-711

38 Fox KAA, Piccini JP, Wojdyla D, et al. Prevention of stroke and systemic embolism with rivaroxaban compared with warfarin in patients with non-valvular atrial fibrillation and moderate renal impairment. Eur Heart J 2011;32(19):2387-2394

39 Eikelboom JW, Wallentin L, Connolly SJ, et al. Risk of bleeding with 2 doses of dabigatran compared with warfarin in older and younger patients with atrial fibrillation: an analysis of the randomized evaluation of long-term anticoagulant therapy (RE-LY) trial. Circulation 2011;123(21):2363-2372

40 Hohnloser SH, Hijazi Z, Thomas L, et al. Efficacy of apixaban when compared with warfarin in relation to renal function in patients with atrial fibrillation: insights from the ARISTOTLE trial. Eur Heart J 2012;33(22):2821-2830

41 Kaatz S, Kouides PA, Garcia DA, et al. Guidance on the emergent reversal of oral thrombin and factor Xa inhibitors. Am J Hematol 2012;87(Suppl 1):S141-S145

42 Hankey GJ, Eikelboom JW. Dabigatran etexilate: a new oral thrombin inhibitor. Circulation 2011;123(13):1436-1450

43 Wallentin L, Yusuf S, Ezekowitz MD, et al; RE-LY investigators. Efficacy and safety of dabigatran compared with warfarin at different levels of international normalised ratio control for stroke prevention in atrial fibrillation: an analysis of the RE-LY trial. Lancet 2010;376(9745):975-983

44 Van Spall HG, Wallentin L, Yusuf S, et al. Variation in warfarin dose adjustment practice is responsible for differences in the quality of anticoagulation control between centers and countries: an analysis of patients receiving warfarin in the randomized evaluation of long-term anticoagulation therapy (RE-LY) trial. Circulation 2012;126(19):2309-2316 